\title{
Novel Consideration Regarding the Role of Evoked Potential in Confirming the Diagnosis of Eye Movement Disorders of Brainstem Origin
}

\author{
Szabolcs Tóth*
}

Currently, it is generally accepted that Brainstem Acoustic Evoked Potential (BAEP) may be used to diagnose functional disorders of brainstem origin. However, it is clear that the acoustic evoked potential gives proper information of the function of only a part of the brainstem. Therefore, it seems necessary to involve the examination of the functional disorder of the sensory and motor segments of the brainstem and the functional disorder of the border zone of the diencephalon having direct connection to the brainstem to the examination. The acoustic evoked potential examination of the first, $10 \mathrm{msec}$ long section and the second $10 \mathrm{msec}(10-20 \mathrm{msec})$ long section can be well used to determine the functional disorder of the latter area, as seen in case of severe, traumatic conditions of the brainstem. Severe disorders may be present in the second $10 \mathrm{msec}$ long segment even if the first $10 \mathrm{msec}$ long segment is intact. Lesions of the sensory and motor pathways in the brainstem lead to increased conduction time, and impaired sensory and motor functions, often on the opposite side.

Studies show that evaluation of the functional disorder of the brainstem is easier and more unequivocal when examined with multimodal evoked potential compared with the examination of only the first $10 \mathrm{msec}$ of the evoked potential of the brainstem. Changes in the multimodal evoked potentials are better and more reliable methods to determine the potential changes in brainstem conditions which are often severe.

Author was deceased at the time of publication

S. Tóth, M.D.

University Professor, DMSC Neurosurgeon,

Electrophysiologist, Budapest, Hungary 